\title{
GEOGRAFARESS \\ O VITALISMO E O PENSAMENTO GEOGRÁFICO MODERNO
}

Revista do Programa de

Pós-Graduação em Geografia e do Departamento de Geografia da UFES

JANEIRO - JUNHO, ZOZI

ISSN 2175-3709

PAULO CESAR SCARIM

paulo.scarim国ufes.br

Artigo recebido em:

17/08/2020

Artigo aprovado em:

[1/03/2021
VITALISMO Y PENSAMIENTO GEOGRÁFICO MODER-
NO

VITALISM AND MODERN GEOGRAPHICAL THOUGHT

VITALISME ET PENSÉE GÉOGRAPHIQUE MODERNE

\section{RESUMO}

O pensamento geográfico esteve no centro das formulações filosóficas e científicas entre meados do século XVIII e início do século XX. Este período também representou uma grande influência do pensamento vitalista. Neste trabalho apresentamos elementos para compreender a relação e mútua influência entre o vitalismo e o pensamento geográfico neste período do pensamento moderno.

palavras-chave: Pensamento Geográfico, Vitalismo, História do Pensamento.

\section{RESUMEN}

El pensamiento geográfico estuvo en el centro de las formulaciones filosóficas y científicas entre mediados del siglo XVIII y principios del siglo XX. Este período también representó una gran influencia del pensamiento vitalista. En este trabajo presentamos elementos para comprender la relación e influencia mutua entre el vitalismo y el pensamiento geográfico en este período del pensamiento moderno.

PALABRAS-CLAVE: pensamiento geográfico, vitalismo, historia del pensamiento.

\section{A BSTRACT}

Geographic thinking was at the center of philosophical and scientific formulations between the mid-18th century and the beginning of the 20th century. This period also represented a great influence of vitalist thinking. In this work we present elements to understand the relationship and mutual influence between vitalism and geographical thinking in this period of modern thought.

KEYWORDS: Geographical Thought, Vitalism, History of Thought.

\section{RÉSUMÉ}

La pensée géographique était au centre des formulations philosophiques et scientifiques entre le milieu du $18 \mathrm{e}$ siècle et le début du 20e siècle. Cette période a eu, également, une grande influence de la pensée vitaliste. Dans cet article, nous présentons 
quelques éléments pour comprendre la relation réciproque entre vitalisme et pensée géographique tout ao long de cette période de la pensée moderne.

MotS CLÉS: Pensée géographique, Vitalisme, Histoire de la pensée.

\section{NTRO DUÇÃ O}

Este texto busca contribuir para a reflexão sobre a importância do pensamento Vitalista no pensamento geográfico moderno a partir do exame do próprio pensamento Vitalista. Definir o Vitalismo é uma tarefa arriscada devido a sua abrangência, antiguidade, muitas renovações e releituras. Aqui cabe apontar a situação deste pensamento no momento de renovação do pensamento geográfico a partir do século XVIII. A importância do Vitalismo neste período está em relação com os limites, obstáculos, deslocamentos, problemas e paradoxos do pensamento físico-matemático, sintetizado aqui no termo Mecanicismo, incapaz de "explicar satisfatoriamente, por exemplo, os fenômenos ligados à vida, com o passar do tempo, chamando atenção de alguns filósofos interessados na matéria" (Duarte,1993, p.37).

Seus limites ficam evidentes quando necessitou adentrar no âmago do organismo. Este dualismo (Mecanicismo/Vitalismo) estará presente em boa parte do debate científico - filosófico, pelo menos de Imanuel Kant (1724-1804) a Ernst Haeckel (1834- 1919). Seria o mecanicismo inútil quando aplicado à Vida? Esta problemática perpassa o surgimento de diversas ideias no âmbito da história natural e na filosofia da natureza, bem como na geologia, anatomia, fisiologia, biologia e geografia. E não é tudo, pois pelo menos desde Baruch Espinosa (1632-1677) um deslocamento para a imanência aventura-se ao buscar explicar o mundo por si mesmo.

A geologia passa por grandes transformações do pensamento na segunda metade do século XVIII, derivando em diversas concepções para além da própria geologia, pois a transformação gradual da superfície da terra coloca em cena a transformação de todas as condições de vida sobre a terra e conduz à reflexão sobre as transformações dos organismos, suas adaptações e, consequentemente, a problemática da variabilidade das espécies. A física com os novos estudos sobre o calor mecânico e a energia coloca como princípio a eterna circulação da matéria em movimento. A química transpõe o abismo entre o inorgânico e o orgânico. A isto se soma as pesquisas de paleontologia, anatomia e da fisiologia comparadas, o emprego do microscópio e do descobrimento da célula, chegando à comparação dos detalhes, tanto em laboratório como quando levado às condições reais das diferentes paisagens

\section{GenGrafaress}

Revista do Programa de Pós-Graduação em Geografia e do Departamento de Geografia da UFES

JANEIRT - لUNHC, 2021 ISSN 2175-3709 
GEOGRAFARESO

Revista do Programa de

Pós-Graduação em Geografia e do Departamento de Geografia da UFES

Janeiro-Junho, 2021

ISSN 2175-3709 da superfície terrestre, dos vegetais e dos animais derivando no surgimento do pensamento biológico. E pelo método da geografia física comparada, estas contribuições, chegam a cada organismo em particular, às suas situações concretas, inclusive naqueles que desafiavam todas as classificações, pois não eram definíveis nem como animais como vegetais.

Estas ideias desfaleceram a ideia fixista e o paralelismo entre a história do mundo inorgânico, do orgânico e de cada ser organismo em particular. Lembrando que CasparWolf (1733-1794) em sua Theoria Generations (1759) partindo de Aristóteles (384a.c-322a.c), Willian Harvey (1578-1657) e da teoria da epigênese questiona a ideia de invariabilidade das espécies, antecipando as obras de Lorens OKen (1779-1851), Jean-Baptiste Lamarck (17441829), Karl Baer (1792-1876) e Charles Darwin (1809-1882). Ou seja, contribuindo para os eventos de 1859. Não era, como se percebe, um pensamento isolado. Como reconheceu Friedrich Engels (1820-1895) no início da década de 1880 na obra Dialética da Natureza: " $a$ primeira brecha nessa concepção petrificada da Natureza foi aberta, não por um naturalista, mas por um filósofo. Em 1755 apareceu a História Natural e Teoria Geral do Céu, de Kant. O Mundo passa a ser visto como algo que se foi formando no transcurso do tempo" (Engels, 1979, p.19). Esta questão é importante, pois a partir de Immanuel Kant (1724-1804), o pensamento geográfico in- fluiu profundamente no debate sobre o sistema da natureza.

Estaria acontecendo uma segunda revolução ou um deslocamento da revolução Copernicana? (Lebrun, 1993, p.323). Se existiu, procuraremos pensá-la no diálogo com o pensamento geográfico. Para Lebrun, nesta "revolução na revolução", ocorreria uma "dissolução da finalidade técnica" (Lebrun, 1993, p.329). Eis a questão: como compreender um corpo organizado? Para Lebrun, Kant expõe um duplo obstáculo à conceituação de organismo, um que leva ao conceito de matéria e suas relações com as forças motrizes e outra que diferencia corpo e matéria, ou seja, à descontinuidade da vida e da matéria. (Lebrun, 1993, p.331). Levando à pergunta: "o que é o vivo?"

\section{O QUE É O VIVO?}

Kant comenta que Herman Boerhaave (1668-1738) "diz em algum lugar: o animal é uma planta cujas raízes estão no estômago. Brincando com estes conceitos, um outro poderia dizer da mesma maneira, sem ser recriminado: a planta é um animal cujo estômago está na raiz" (Lebrun, 1993, p.330). De onde Kant acrescenta outra questão: onde encontraremos então uma separação entre vivo e não vivo? Lebrun afirma que a partir de Kant "um ser organizado não é apenas máquina" (Lebrun, 1993, p.340). Por sua vez, depois de ter lido Kant, Johann Blumenbach (1752-1840) as- 
sente às finalidades naturais atribuindo ao organismo fins naturais: crescimento, reprodução, autoconservação (Lebrun, 1993, p.340). Com fins naturais assume caractere comum: a auto-organização. Estaríamos olhando o mundo por outro ângulo? Este "novo" olhar tem diante de si uma palavra potente: Vida. Seria uma peripécia semântica a proximidade com a "criação orgânica"?

Bensaude-Vicent\&Stengers (1992, p. 87) destacam a importância de Georg Ernst Stahl (1660-1734) e da teoria Vitalista "que recusa a assimilação do ser vivo a uma máquina explicável em termos físicos e químicos", pois a vida reclama um princípio próprio, diferente daquele que oferecia a teoria Mecanicista. Podemos buscar esta questão também em Baruch Espinosa (1632-1677) e David Hume (1711-1776), pois no limite da física encontraram a arte da anatomia. E a relação entre raciocínio, observação e experimentação (Pimenta, 2018, p.30). Em foco está a distinção entre força vital e causalidade.

Interessante e ilustrativo pensar sobre estes limites. Denis Diderot (1713-1784) e Jean d'Alembert (1717-1784) na Enciclopédia, publicada entre 1751 e 1772, com 36 volumes e com contribuições de Rousseau, François-MarieVoltaire (1694-1778), Anne Turgot (1727-1781), Jean-François Marmotel (17231799), Charles Montesquieu (1689-1755), François Quesnay (1694-1774), Paul Holba- ach (1723-1789), em determinado momento se perguntam. O que é um animal? Após uma reflexão e uma demonstração chegam a uma conclusão: "só resta de geral ao animal o que ele tem em comum com o vegetal, vale dizer, a faculdade de se reproduzir". (Diderot e d'Alembert, 2015, pg.143). Diderot fala das "passagens", que "linhas de separação" não existem e de seres organizados "que não são nem uma coisa nem outra". Fala de "minerais menos mortos que outros". Para Diderot, a partir de Georges-Louis Buffon (1707-1788), cabe pensar as "relações". Trata-se aqui do deslocamento da física newtoniana para uma visão organicista e para um sistema da natureza.

A problemática até aqui pode ser assim apresentada: como ampliar a aplicação do método experimental para os corpos, à matéria, à substância, aos seres viventes, aos animais e ao humano e quais as consequências deste importante deslocamento para pensar a Alma e seus correlatos? A imanência se coloca como uma visada, um olhar para o interior e vai chegar à existência de um corpo, dado no tempo e no espaço, como sistema de relações fisiológicas e proporções anatômicas estáveis (Pimenta, 2017, pág.16). Nesta monta a Fisiologia, a Anatomia Comparada e a Medicina Experimental ascendem a um lugar seguro acerca do conhecimento dos corpos organizados. Neste deslocamento da importância dada à leitura do

\section{GenGrafares}

Revista do Programa de Pós-Graduação em Geografia e do Departamento de Geografia da UFES

Janeiro-Junho, 2021 ISSN 2175-370S 
GengRAFARESO

Revista do Programa de Pós-Graduação em Geografia e do Departamento de Geografia da UFES

Janeiro-Junho, 2021 ISSN 2175-3709 corpo a partir dos efeitos, dos sinais e dos sintomas ocorre possivelmente uma inversão onde a Fisiologia acende como princípio filosófico. Estaríamos diante de uma fisiologia filosófica ou de uma filosofia fisiológica? Diderot vai buscar este ponto comum na química. E este ponto se encontra no limiar entre um reino e outro. $\mathrm{E}$ nas fronteiras entre os reinos encontra o sentir e a nutrição.

A pergunta (o que é o Animal?) remete à sua dimensão fisiológica, à definição de Vida. Enquanto coisas naturais, conforme as leis da natureza, que possui funções vitais (respiração), naturais (digestão) e animais (movimento). Neste ponto encontra o encontro, e a distinção, entre a Física e a Química.

Gabriel François Venel (1723- 1775) no verbete Química da Enciclopédia (Venel, 2015, p.313-348) dialogando com diversas teorias da física e da química principalmente com a obra de Johann Joachim Becher (1635-1682), Physica Subterrâneae e com Hermann Boerhaave (1668-1738) provoca uma reflexão sobre o encontro e a distinção da Física mecanicista com a Química organicista. Para ele a química penetra até o interior de certos corpos que a física só conheceu a superficie. Porém, caberia superar as explicações isoladas dos estudos químicos. Por influência do flogistico e do vitalismo, Venel estava esperando um novo Philippus Paracelso (1493-1541). Buscava dar à química o lugar da física, digna da atenção dos filósofos. Ele anunciava a quí- mica geral filosófica. Enquanto a física buscava o conhecimento dos corpos por suas qualidades exteriores, caberia a uma ciência essencialmente distinta estudar os fenômenos da organização, da composição, do orgânico e dos movimentos dos corpos vivos.

Aqui encontramos o debate sobre as distinções entre agregado e corpúsculo e entre as propriedades externas e as qualidades internas e entre as forças físicas e as afinidades químicas. Como também sobre as qualidades particulares, as integrantes e as dependentes umas das outras. Descobrir as qualidades internas dos corpos seria o programa da química anunciada. Trata-se de ações que dependeriam mais das qualidades internas dos corpúsculos do que de choques com corpos e forças externas. Haveria distinções entre as diversas formas de afecções, remontando a Baruch Espinosa (1632-1677).

Trata-se neste contexto de perscrutar os movimentos internos (digestão) que não atuam de modo sensível (instantâneo), pois seguem as leis das afinidades e não os princípios mecânicos. Trata aqui dos corpos, das relações entre os corpos e de seus princípios (propriedades, qualidades químicas, combinações, modificações e relações).

A esta Física subterrânea, que a nova Química anunciava naquele momento, caberia a observação dos fenômenos naturais (maturação, formação, alteração, geração e inflamação) açambarcando com a economia animal, com a botânica física e com os estudos mine- 
rais. Apoiada por estudos experimentais sobre os fenômenos artificiais e laboratoriais ela conhece este corpo, ela é a ciência dos pequenos corpos, ela é uma arte (Venel, 2015, p. 317-333). A arte química realmente deu um passo a mais?

Trata-se de um ponto de vista, o da afinidade. Que possibilita a diferenciação entre agregado e mistura. Esta requer pensar a ligação que cria corpos a partir de outros corpos, a ligação química. A esta, à Química, da passagem do século XVIII ao XIX, interessa a "intimidade das matérias" (Bensaude-Vicent\&Stengers, 1992, p. 94). Esta é a Química das afinidades, fundamental para entender Antoine-Laurent de Lavoisier (1743-1794) em seu Traité Élémentaire de Chimie, de 1789. A ideia de afinidade química foi fundamental para esta elaboração, pois se liga à transformação da matéria inorgânica e orgânica. É central também para entender a obra de Alexander Humboldt (1769-1859), vide por exemplo em no Cosmos (Humboldt, 1859, pg.10-11). Esta questão remete ao próprio lugar da química no pensamento da filosofia natural. A matéria vista como composta de corpúsculo cujas propriedades não se reduzem a propriedades mecânicas está na base do pensamento químico a partir daquele momento. Assim como no pensamento geográfico.

\section{O QUE É O MEIO?}

A noção de Meio surge a partir deste pensamento quí- mico. Buscando estudar os compostos orgânicos como fenômeno da fronteira e avançando além dela própria a Química Orgânica, como uma parte da fisiologia, descreve a "composição dos corpos vivos e os processos químicos que ai produzem" (Bensaude-Vicent\&Stengers, 1992, p. 184).

O enigma daquilo que está vivo: assim Walter Benjamin (1892-1940) expõe a tarefa das inquietações de Johann Wolfgang Von Goethe (17491832). A fenomenologia de Goethe é uma via fundamental deste pensamento químico como pensamento geográfico. A noção de Meio percorre toda a obra Afinidades Eletivas. Goethe parte de um lugar comum a Johann Kaspar Lavater (1741-1801), e sua fisiognomia, e Johann Gottfried Herder (1744-1803), e sua concepção histórica, para pensar a anatomia. A este interessa a anatomia como método e o coloca em contato com Johann Friedrich Blumenbach (17521840) e influencia este no momento da escrita do Manual de Anatomia Comparada, de 1805. Estes diálogos estão na base da teoria dos tipos.

Estudar as naturezas orgânicas e suas metamorfoses, a aparição de tipos propiciados pelas relações e reações físico-químicas que acontecem e produzem o meio, é um objetivo comum de diversos pensamentos, seguindo o método de partida da Fisionomia comparada.

O pensamento geográfico dialoga com esta construção físico-química da noção de

\section{GeEGRAFARESO}

Revista do Programa de Pós-Graduação em Geografia e do Departamento de Geografia da UFES

Janeiro-لunho, 2021

ISSN 2175-370S 
GengRAFARESO

Revista do Programa de Pós-Graduação em Geografia e do Departamento de Geografia da UFES

Janeiro-Junho, 2021 ISSN 2175-3709
Meio. Alexander Humboldt (1769-1859) manteve também relações intelectuais intensas com Blumenbach e ampliou os elementos da fisionomia para a vegetação. A Geografia Comparada de Carl Ritter (1779-1859) teve também em sua base os estudos de fisiologia e anatomia de Blumenbach, travando contato com as teorias de Carl Linné (17071778), Georges-Louis Buffon (1707-1788) e Georges Cuvier (1769-1832).

Humbold em sua obra Cosmos demonstra que a descrição dos fenômenos, mesmo exata ou precisa não é incompatível com a pintura animada e viva das cenas (Humboldt, 1859, pg.10-25). Nele a descrição física da terra torna-se descrição fisiológica do mundo. E esta requer um plano. Bem Kantiano. Este plano incluiu uma meticulosa preparação que Humboldt realizou antes de suas longas viagens. Ele estudou História Natural em Gottinguem com Blumenbach, realizou estudos geológicos na Academia de Minas, aprofundou os estudos de Anatomia e física em Viena, dialogou sobre a força vital com Friedrich Schiller (1757-1805), sobre eletricidade animal com Luigi Galvani (1737-1798) e sobre as metamorfoses com Goethe. Nesta preparação participaram a botânica (e a zoologia), a geologia (e o vulcanismo), a química (e o vitalismo), a física (e a astronomia) e as técnicas instrumentais (e o magnetismo terrestre). Aprende com estas ciências especiais que para compreender o fundo dos fenômenos em sua influência mútua deveria se guiar pela sequência mesma das coisas que alimentam umas às outras.

A observação e o conhecimento da conectividade das forças da natureza se colocam em aliança com o sentimento íntimo de sua dependência mútua. Mantém uma tradição da filosofia da natureza e do sentimento profundo da harmonia do todo da natureza, agora articulada com uma visão racional, observadora e experimentadora. Isto para dar conta da descrição dos fenômenos celestes e terrestres, desde fenômenos distantes, com a física, como sobre o conhecimento dos fenômenos orgânicos e celulares, com a química. Além da imensidão do cosmos e da diversidade das formas e dos organismos, deve dar conta dos mistérios primordiais da vida, suas transformações e suas metamorfoses, assim como das aglomerações dos corpos celestes à da distribuição dos organismos terrestres. Cabe na calma da natureza, pensar que cada organismo é parte de um todo, não formas isoladas, mas ligadas à cadeia dos seres vivos, inclusive os extintos (Humboldt,1859, pg.23-25).

Karl Ritter (1779-1859) é explícito ao dizer, em seu Erdkunde ou Ensaio Introdutório à Geografia Geral Comparada, que ele chamou de comparativo foi no mesmo sentido em que essa palavra 
era aplicada aos ramos principais da ciência, por exemplo, a Anatomia Comparada. Assim como Johann Georg Adan Forster (1754-1794), Goethe e Humboldt estabeleceram relação com o botânico Georg Franz Hoffmann (1760-1826). É possível citar a relação entre Johann Heinrich Pestalozzi (1746-1827) e Ritter e a questão dos instintos e dos métodos naturais. Ritter pensou as diversas partes do mundo como organismos vivos e influenciou na ideia metafórica de George Wilhelm Friedrich Hegel (1770-1831) de que os continentes são indivíduos.

Por sua vez, esses foram influenciados por Johan Gottfried Herder (1744-1803) pela questão da relação entre gênio e espaço como uma revelação. Herder foi aluno de Immanuel Kant (1724-1804) em Koningsberg e influenciou diretamente na Filosofia da Natureza de Friedrich Wilhelm Joseph Schelling (17751854). Ou seja, uma confluência de pensamentos que se transformam. Humboldt e Aimé Bonpland (1773-1858) ampliam a ideia de força vital para o conjunto da natureza interconectando o físico, o geológico, o químico, o biológico e o cultural. Esta naturgemälde dialoga com a naturphilosophie de Schelling.

A química coloca em cena a força da transmutação, herança da alquimia, em Lavoisier, Michael Faraday (1791-1867) e Justus Von Libieg (18031873), entre outras figuras pensantes desta passagem do século XVIII para XIX. O pensamento químico repensa o Vitalismo. De que forma? Pensemos nos reinos de Linné e sua correlação de permanência em Buffon, em seu plano de fundo fixista e finalista, no equilíbrio e na harmonia das forças.

Esse pensamento químico permitiu conjecturar sobre a continuidade das coisas, dos processos e dos elementos (do inorgânico para o orgânico, por exemplo), em transformações e em transmutações (da quantidade para a qualidade, outro exemplo). Qual a relação de forças que produz modos e se modifica?

Neste ponto entra o atomismo, a substância, o corporium, as partículas e os elementos. Este debate é central, o do mecanicismo-vitalismo, pois coloca em cena o corpo e seus órgãos, como sendo corpo-vivo, como organismo. E o humano? Esta é uma questão que deve ser resolvida, pois, este, o corpo, além de coisa extensa é coisa viva (ser vivo, organismo vivo, meio vivente...). Além disso, é ser vivo pensante, é aquele que vive e que sabe que sabe. Desta forma, a Química, e por esta a Biologia nascente, resgata a ideia do ser como coisa pensante, mas dá destaque à relação do interno e do externo do ser e recoloca o grande tema da imanência, agora sob a forma de metabolismo.

A Anatomia Comparada, a Fisiologia e a Química passam

\section{GenGRAFARESO}

Revista do Programa de Pós-Graduação em Geografia e do Departamento de Geografia da UFES

Janeiro-Junho, 2021

ISSN 2175-3709 


\section{GEOGRAFARESO}

Revista do Programa de Pós-Graduação em Geografia e do Departamento de Geografia da UFES

Janeiro-Junho, 2021

ISSN 2175-3709 a ser os exemplos das ciências experimentais com suas próprias artes igualmente experimentais. A física experimental seria (ou poderia ter sido?) a ponte entre a abordagem mais abstrata e a mais concreta? " $E$ $o$ que se oferece ao filósofo adepto ao método experimental é uma espécie de quadro da natureza, em que a imagem do mundo é consideravelmente mais complexa do que aquela ordem inabalável em que trabalham os newtonianos" (Pimenta, 2018, p.176)

Diderot parte da distinção entre observação e interpretação da natureza. A primeira é a aplicação do método experimental em laboratório, a experimentação, o experimento e a experiência. A segunda é conjectural e como principia norteadora das ciências naturais é epistemológico. Diz respeito a relação sujeito-objeto, a utilidade-resultado e o círculo epistemológico sentidos-reflexão-sentidos: " $h a ́$ uma metafísica natural, gestada do contato mais imediato entre o homem e o mundo à sua volta". O olhar, o provar, o escutar, a sensação e a reflexão "só permitem conhecer a natureza quando conectadas entre si, como se formassem um circuito, em que as peças estão ligadas pelo fio da sensibilidade, ou do sistema nervoso: unidade orgânica que antecipa e espelha a dos seres organizados fora do homem." (Pimenta, 2018, p.181). Coube a Marie Bichart (1771-1802), "como bom 'vitalista', formular o axioma fundamental da fisiologia como ciência, mais do que experimental, comparativa: 'vie est l'ensemble dês fonctions que résistent à mort". Esse 'famoso aforismo' estaria na base das formulações ulteriores de Claude Bernard, cuja teoria permitirá à Morfologia estrutural decifrar as variações de formas de diferentes espécies que habitam um mesmo meio como 'diferenças fisiológicas' determinantes para exigências ditadas pelo meio que habita" (Pimenta, 2018, p.241). No limiar novamente está a distinção entre meio interno e externo. Há a hipótese da existência de um espaço onde a vida existe. "O que significa falar de um corpo, como se tivesse um centro e uma circunferência - como se ele fosse uma forma geométrica?" (Pimenta, 2018, p.244). Trata do isolamento do corpo, enquanto ambiente interno, dos outros corpos, para estudá-lo. Trata da distinção entre o vivente e seu meio, onde as forças vitais garantidora da conexão e unidades das partes opõem-se às forças à atuação externa, forças destrutivas. Para isso deve-se buscar uma linguagem própria. Porém como esta ser definida por analogias às existentes na ciência mecânica e este é o desafio da fisiologia. $\mathrm{E}$ "o que se quer dizer com vida, quando se pronuncia essa palavra? E o que implica referi- la a um suporte - o organismo?". (Pimenta, 2018, p.245)

Como lembra Georges Canguilhem (1904-1995) para Claude Bernard (1813-1878) o organismo é apenas "um vivente vivendo como um", ou seja, 
como um Todo (Canguilhem, 1965, p.19). Questões importantes se colocariam como obstáculos à ampliação da ciência experimental ao conjunto da vida: a especificidade das formas vivas, a diversidade dos indivíduos, a totalidade do organismo e a irreversibilidade dos fenômenos vitais. Porém obstáculos estimulantes, pois a complexidade dos fenômenos da vida deve comandar a experimentação na física, na química, na biologia, na medicina. Na Geografia também? Pois se um conteúdo escapa ao outro é possível estender ao outro também como conteúdo derivado. Vide Linée como o mestre do fixismo, mas que ao longo da vida dúvida da tese, podendo inclusive ser colocado como um dos fundadores do transformismo. Pois o olho ao observar o mundo por um microscópio o que vê? $\mathrm{O}$ vivo composto de célula. E a olho nu? O mesmo vivo composto de biosfera.

É o prolongamento da vista e do pensamento. Pensar que a célula não é uma parte e que o ser não é um composto de minúsculas partes (as células). Mas pensar que a célula é o único componente de todos os seres vivos, incluindo a biosfera, e que uma célula provém de outra célula e não de um exterior, é um deslocamento considerável no pensamento. Isto funda a teoria celular. Mas as ideias possuem percursos cambiantes. Passando pela de um favo de mel, de um pequeno quarto de mosteiro, da ideia de trabalho, de afinidade, de afetividade, de grão, de semente, de organização, de composição, de decomposição, de algo depositado, ou imanente. E muitas analogias. Ou como pergunta Friedrich Ratzel (1844-1904) em 1901: "Não poderíamos dizer que o enfrentamento espacial [Raumbewältigung] é um fenômeno geral da vida e uma marca da vida?" (Ratzel,2019, pg. 112).

Coetâneos, nascidos e escrevendo no mesmo momento, Linée (1707-1778) em seu Systema Naturae de 1735, Buffon (1707-1788) em seu Histoire générale des animaux de 1749, Albrecht Haller (1708-1777) no Elementa Psysiologiae de 1757 e Pierre Maupertius (1698-1759) no Venus Physique de 1745, vão colocar questões importantes neste debate. Para Haller " $A$ fibra é para o fisiologista o que a linha é para o geômetra" (Canguilhem, 1965, p.49). Buffon desenvolve a teoria da composição dos viventes como um sistema. Maupertius diz que "por trás da afinidade, é preciso perceber a atração". Buffon diz que a nutrição, o desenvolvimento e a reprodução do vivente se fazem por outras leis que não a da mecânica comum. Colocando a dúvida sobre as forças penetrantes e atuantes nas massas dos corpos, nos pesos dos corpos, nas atrações magnéticas e nas atrações químicas. Por que não admitir? George Cuvier (1769-1832) em sua Leçons d'anatomie comparée (1805) toca na resposta, ao afirmar que a ideia de vida é uma ideia geral produzida em nós "por

\section{GenGRAFARESS}

Revista do Programa de Pós-Graduação em Geografia e do Departamento de Geografia da UFES

Janeiro-لunho, 2021

ISSN 2175-3709 


\section{GEOGRAFARESS}

Revista do Programa de Pós-Graduação em Geografia e do Departamento de Geografia da UFES

Janeiro-Junho, 2021

ISSN 2175-3709 certas sequências de fenômenos, que vemos se sucedendo em uma ordem constante e sendo mantidas juntas por relações mútuas. Embora não conheçamos a natureza daquilo que os une, sentimos que esse elo deve existir". Para Cuvier nosso próprio corpo parece "resistir por um certo tempo às leis que governam os corpos bruts, e até mesmo agir sobre tudo o que os rodeia, de uma maneira totalmente contrária a essas leis, usamos os nomes da vida e da força vital para designar essas exceções, pelo menos aparentes, às leis gerais" (Cuvier, 1805, pg. 1-2).

Buffon, com a questão das forças penetrantes e o molde interior, está a meio caminho entre a causa formal de Aristóteles e o meio interno de Claude Bernard. Desta forma parte do cálculo matemático (princípios mecânicos), passa pelas ciências físicas (forças penetrantes, peso...) e chega às ciências naturais pensando sobre a ação das forças penetrantes nos corpos organizados. Assim Buffon estende a atração a todos os fenômenos da matéria viva, estendendo assim o entendimento da matéria aos seres vivos, às moléculas orgânicas, ao fogo, à luz e ao calor, isto é, a "toda matéria que nos parece ativa por si mesma" (Canguilhem, 1965, p.54).

Qual nome? Sistema, princípio, conjunto, força vital? Há uma afinidade entre a teoria celular, molecular, atômica com a ideia de vitalidade. Esteve presente em Lorenz
Oken (1779-1851), bem como foi uma ponte entre a escola romântica de Friedrich Schelling (1775-1854) e os médicos e biólogos. Esteve presente na Universidade de Iena, em Theodor Scheleiden (1810-1882) que estudou as células vegetais e a phytogenesee e em Theodor Scwann (1810-1882) que generalizou a teoria a todos os seres vivos. Assim a teoria celular e o vitalismo de Paul-Joseph Barthez (1734-1806) são coetâneos do gosto europeu no século XVIII pela História Natural. As descrições avolumam-se. Os Gabinetes de História Natural, as Coleções de História Natural, as Academias de Ciência, as Sociedades Reais, os Jardins e os Hortos e depois as exposições. É neste contexto que influencia os Princípios de Filosofia Zoológica (1830) de Étienne Saint-Hilaire (17721844) e o debate com Georges Cuvier.

\section{O QUE É UMA DES- CRIÇÃO?}

Para Louis Daubenton (1716-1799) "descrever as diferentes produções da natureza é traçar o seu retrato, é compor um quadro que as represente, tanto o seu interior quanto o seu exterior, sob aspectos e estados diferentes" (Daubenton, 2015, pg.185)

A questão é a extensão do objeto da história natural a ser descrita. O universo inteiro?

\footnotetext{
"A descrição das produções da natureza é a base de sua história, é o único meio para reconhecer cada uma delas em particular e dar
} 
uma ideia justa de sua conformação[...] Mediante tais transformações, pode se comparar um objeto a outro...Se o naturalista considera uma coisa, é para compará-la a outra" (Daldenton, 2015, pg.219220).

Uma anatomia, que contempla cada coisa em si mesma, um olhar a partir do particular. E assim, comparando as partes e os seres entre si, conheceria melhor os seres em particular e a mecânica da natureza em geral. Este seria então o objeto da anatomia comparada, para Dalbenton. A medicina seria um ramo da história natural. Pois o ser humano é um animal. Desta forma, e com base na Anatomia Comparada, teríamos uma medicina comparada e uma cirurgia comparada. E neste método separar é correlato a nomear. Assim também a botânica no século XVIII, cuja uma das suas finalidades é conhecimento das qualidades das plantas começando pelo "exame detalhado das partes" (Daubenton, 2015, p.223), teria imanente uma espécie de Anatomia.

$\mathrm{O}$ avanço destas anatomias colocou luz também sobre as relações entre gêneros, espécies e famílias. No verbete História Natural Daubenton diz que pode-se "comparar a seiva das plantas ao sangue dos animais ou ao líquido dos animais que não tem sangue. As plantas obtêm nutrição pela sucção realizada por raízes $e$ folhas, assim como os animais pela boca ou por sugadores. Ocorre nas plantas digestão, secreção, evacuação" (Daubenton, 2015, pg.224). Entre os reinos (mineral, vegetal, animal) existem muito mais relações.

Enquanto o Naturalista pesquisa as produções da natureza, observa, até toca, ele procura com delicadeza e cuidado para não as deformar. Bem diferente é o Químico que anseia, como um artista, a decompor as produções da natureza, até chegar ao pequeno, às partículas, às moléculas, aos elementos, aos princípios e aos primeiros. A Química: "essa ciência começa no ponto em que a História Natural termina" (Daubenton, 2015, p.224).

Fica evidente que um gosto europeu no século XVIII pelas descrições, pelas observações e pelos sistemas da natureza. Quem percorreria a superficie inteira da terra para ver as produções de cada clima e de cada país? Os naturalistas. Jardins, coleções e gabinetes representaram a ideia de um resumo da natureza inteira. Tudo dispostos em ordem aos olhos do observador. Os gabinetes representaram o lugar de aprendizado das primeiras noções dessa ciência, como um método: "após tê-los considerados em seus gabinetes, é conveniente ler, numa obra bem escolhida, sua descrição e história, antes de passar à observação de um objeto no seio da natureza". Para Daubenton os fatos da história natural são estabelecidos por relações (entre coisas e seres naturais) e cabe ao naturalista compará-los. As combinações são os objetos de meditação dos naturalistas (Daubenton,

\section{GenGRAFARESO}

Revista do Programa de Pós-Graduação em Geografia e do Departamento de Geografia da UFES

Janeiro-Junho, 2021

ISSN 2175-3709 


\section{GEOGRAFARESO}

Revista do Programa de Pós-Graduação em Geografia e do Departamento de Geografia da UFES

Janeiro-Junho, 2021

ISSN 2175-3709
2015, p.227-229).

Os naturalistas até aquele momento se dedicaram e se contentaram a classificar e a descrever as partes, os órgãos e as diferenças, mas coube a partir daquele momento compará-los entre si e por inteiro as relações entre as partes e expor a ordem da natureza no particular e no geral. A divisão das diferentes produções da natureza deveria ser metódica (Diderot\&D’Alembert, 2015, pg.233) principalmente pela quantidade de objetos, suas estruturas, suas qualidades e suas propriedades. Representando uma passagem de uma visão externa para uma visão interna dos objetos. Porém representou uma dificuldade, um obstáculo e um limite epistemológico.

Como diz Holbach, no verbete Minerais, esse "conhecimento externo dos corpos é estéril e infrutífero; e como a História Natural deve ter em vista a utilidade para a sociedade, é preciso ter um conhecimento das qualidades internas das substâncias minerais para saber em que elas podem ser empregadas, conhecimento esse que só pode ser fornecido pela Química" (Holbach, 2015, pág. 241). Desta forma residiu na Química o fundamento da Fisiologia, nela se encontrou a ligação entre o animado e o inanimado e coube a essa ciência realizar a ponte entre a História Natural e Física.

\section{E O QUE É VITAL?}

Mas a definição de vida carregou paradoxos: é um efeito, uma forma, um signo e uma articulação sistemática. É um impulso tal como o bildungstrieb, de Blumenbach.O que é uma forma, senão o efeito de uma força formadora ou impulso formante? $\mathrm{O}$ que é a vida, senão o efeito de uma força vital? Para Holbach trata-se de uma atividade, a de cumprir as necessidades vitais, um movimento constante do interno para o externo. Estamos diante da ideia de uma formação imanente, como o bildungstrieb e uma formação transcendente como a bildungskraft de Kant. Sentido bem diferentes para formação.

$\mathrm{O}$ que nos encaminha para o diálogo com a concepção de Jean Baptiste Lamarck (17441829) em Philosophie Zoologique de 1809, que busca a causa estimulante das excitações. E vai buscar em outra linguagem do vitalismo, a da escola de Montpelliere em Pierre-Jean Cabanis (17571804) e a encontra na irritabilidade, enquanto propriedade intrínseca dos corpos animados. Juntamente com Cabanis, Antoine Destrutt de Tracy (1754-1836) e Étienne Condillac (1714-1780) fazem do tato a fonte primordial das ideias. Daí nasce uma teoria fisiológica da sensibilidade. Por que não uma filosofia?

Esta questão está presente nas ideias de Arthur Schopenhauer (1788-1860) principalmente no $O$ Mundo como Vontade e Representação e Sobre a vontade na natureza $\mathrm{e}$ o diálogo fraterno e dionisíaco provocado por Friedrich Nietzsche (1844-1900) na obra Genealogia da Moral (1887) 
onde diz que "o homem preferirá ainda querer o nada a nada querer" (Nietzsche, 1998, pg.149). Para Lamarck quando a Biologia integrando a Física formula uma teoria fisiológica da sensibilidade ela faz na linguagem filosófica. Assim Lamarck, Cuvier e Claude Bernard tem muito em comum: "como resultado de um processo, a vida se encontra no meio interior, que mantém relações, mais ou menos conflituosas ou harmônicas, com o meio circundante ou exterior, e, quanto mais complexo o organismo maior a sua interdependência em relação a este" (Pimenta, 2018, p.258).

Há um princípio que atua, como uma energia, diferente da força de gravitação: é a força vital. Há formas geométricas, mas há distinção entre espaços (interior e exterior). Há a Geometria como uma regra geral e há um espaço abstrato e neutro, porém, povoado de corpos particulares, ativos, viventes e orgânicos.

É a ideia de posição que se apresenta. Daí a importância da localização e da cartografia. Porém para Paul Vidal de La Blache (1845-1918) este traço topográfico (Olinto Marinelli, in La Blache, 1901, 2012 pág.114), este onde, não é tudo. Ele acrescenta o de onde? E o porquê? (La Blache 1901, 2012 pág.114). Ratzel em Antropogeografia já tinha apresentado o como? Por este caminho o pensamento geográfico pensou sobre as relações, os tipos e as composições.

Há um esquema. Há uma arquitetura, como em Kant. Seria a Crítica da Razão Pura um pequeno tratado para uso dos naturalistas? Há a ligação entre o peculiar, o particular, as formas e os modos às figurações gerais. Para Pimenta Humboldt aproveita uma intuição presente em Goethe e Geoffroy Saint-Hilaire: " $a$ ideia de que o organismo, ao se posicionar diante do meio, contribui para moldá-lo, no ato mesmo de realização de suas necessidades fisiológicas. Sem propriamente suprimir a ideia de conflito entre os seres vivos e as condições de existência, essa ideia institui uma relação dinâmica entre pólos que tendem à oposição." (Pimenta, 2018, p.259). Questão fundamental para pensar sobre o ato da descrição: "quando se descreve um ser, é preciso observar as relações entre ele e os outros seres da natura" (Daubenton, 2015, pg.185).

\section{A GEOGRAFIA É UMA ANATOMIA?}

Há uma analogia entre os seres e entre os reinos. Segundo Pimenta (2018, p.176) Buffon nos ensinou " a ver corpos em movimento não somente no sêmen dos animais como também nas sementes das plantas". Ou entre o corpo e o meio. Para Pierre Tarin (17251761) "essa analogia não apresenta nada que surpreenda os médicos, pois os sucos dos animais diferem daquele dos vegetais por um grau apenas, e os nossos não são diferentes daqueles dos animais" (em referência a Boerhaave).

\section{GenGrafarest}

Revista do Programa de Pós-Graduação em Geografia e do Departamento de Geografia da UFES

Janeiro-Junho, 2021

ISSN 2175-3709 


\section{GEOGRAFARESO}

Revista do Programa de Pós-Graduação em Geografia e do Departamento de Geografia da UFES

Janeiro-Junho, 2021

ISSN 2175-3709
Tarin divide o corpo em partes, "a fim de evitar confusão", como segmentado em planos: "a anatomia é uma espécie de geografia, e a precisão lhe é indispensável"..."por isso, o corpo, à maneira da Terra, foi dividido em diversas regiões". (Tarin, 2017, p.131-132). É um diálogo entre as pranchas de Anatomia e as descrições das diferentes regiões. E suas cartografias.

Muitas analogias presentes na Física (alavancas, cordas, tubos, máquinas...) e na Química (filtros, alambiques, recipientes, serpentinas...) com o corpo humano. Neste pensamento, o todo possui realidade objetiva e subjetiva e o orgânico é um ser. Isso foi influência de Kant e sua ideia de unidade da superfície da Terra e da natureza. Esta noção de unidade viva da natureza possibilitou seu desdobramento em ciência das obras da natureza. Kant, na introdução à sua physiche erdbeschreibung (descrição física da terra), diz que esta é a primeira parte (propedêutica) do conhecimento do mundo. O que requer uma antecipação, uma ideia, um conceito preliminar de tudo, um plano. É preciso mais do que ver. Precisamos conhecer ao todo, como um sistema. O Todo é o mundo. E sua descrição é primordial. $\mathrm{E}$, para isso, precisamos de um ordenamento prévio, uma classificação quanto aos conceitos (lógica, por exemplo, em Linné) e quanto ao tempo e espaço onde são encontrados.

A descrição geográfica (physiche erdbeschreibung) deve estar de acordo com os lugares que os conceitos ocupam na
Terra. A geografia, desta forma, em Kant diz respeito aos fenômenos que em relação ao espaço acontecem ao mesmo tempo. Refere-se aos acontecimentos que caminham um ao lado do outro no espaço. Para Kant, a história da natureza contém a diversidade da geografia e se expusermos os acontecimentos de toda a natureza através de todos os tempos, se considerarmos ainda as transformações dos animais, das plantas e das demais coisas comparadas, assim como as transformações que se sucedem mediante diferenciação de áreas (ou verschiedenheit des landes) teremos o fundamento da história natural. Conclui-se, portanto, que o acontecimento para acontecer tem, necessariamente, que se relacionar com alguma coisa e acrescentemos e em algum lugar.

Para esta Geografia natural, isto é, esta Geografia dos seres vivos, as relações e suas leis gerais formariam uma harmonia telúrica, como um todo coerente, como um corpo, atravessando os reinos (mineral, animal e vegetal) como uma só linha condutora do pensamento. Estes fatos análogos possibilitaram a analogia com o método da Anatomia comparada. Esta Geografia pensa agora o quadro vivo, o quadro da natureza, como uma unidade e um conjunto. Este todo seria um corpo físico constituído e animado por forças naturais como um sistema diversificado de fenômenos que respeita as individualidades. 


\section{O QUE PODE SER UM VIVO?}

Eventos, como o terremoto de Lisboa, em 1755, estremeceram as bases do pensamento fixista e interessaram muito a Kant. Para ele, estes eventos tectônicos colocam em evidência o conceito de tempo e a capacidade da razão pura na sua relação com a prática e a ética. É possível conhecer o tempo no futuro? Dito de outra maneira: o que pode um corpo diante das forças cósmicas, geológicas, naturais, já que estas constituem um complexo campo de forças? Este tectonismo inexorável é sistematizado por Charles Lyell (1797-1875) em seu Principles of Geology de 1830-1833.

Estava plantada no pensamento sobre a natureza a questão da influência recíproca da Terra e de seus habitantes, entre os mundos inorgânico, orgânico e humano, assim como, a influência da mecânica na totalidade da vida. Trata-se, também, portanto, da passagem e relação entre inorgânico e orgânico. E, é tributário, no século XVIII, do debate da geologia (netunismo e tectonismo) e da biologia (mecanicismo e vitalismo).

A questão de Spinoza, o que pode um corpo? é reformulada da seguinte forma: Como um ser vivo (corpo e coisa pensante) relaciona-se com seu meio, é por ele determinado e o que ele pode? As forças atingem o corpo, e daí? O corpo busca a energia, e daí? Responder a esta questão propiciou um entrecruzamento de ideias que derivou em uma resposta possível pelo pensamento geográfico. Porém, este encontrou limites epistemológicos. Estaríamos diante de uma segunda revolução copernicana, já foi dito. Se a primeira permite a ideia do sistema universal, a segunda permite olhar o corpo como um sistema altamente complexo em si mesmo. Coloca as relações entre centralidades e espacialidades: o Todo, o Sol, a Terra, o Corpo e a Mente. É o meio, como vimos. É a questão de Humboldt: as plantas e todos os seres vitais, na sua existência e suas experiências possuem determinações (temperatura, umidade...) químicas, físicas e biológicas. Daí o método fisiográfico e seus estudos sobre as distribuições e as relações entre os seres vivos.

Levando adiante as proposições de Kant, Goethe, Lavater, Lavoisier e Blumenbach, Humboldt vai extrapolar o método experimental para a natureza nas formas e nos modos como se apresenta diretamente à experiência em campo. Como uma Anatomia penetra na natureza e em seus quadros para depois comparar e chegar a partir da intuição intelectual à ideia do Todo Harmônico, à ideia de Cosmos.

Este entrecruzamento fica bem visível na retomada da antiga questão do clima, feita a partir de Maupertius e Buffon, aliada agora à Geografia das plantas e dos animais, feita a partir de Humboldt,

\section{Gengrafarest}

Revista do Programa de Pós-Graduação em Geografia e do Departamento de Geografia da UFES

Janeiro-Junho, 2021

ISSN 2175-3709 


\section{GenGRAFARESO}

Revista do Programa de Pós-Graduação em Geografia e do Departamento de Geografia da UFES

Janeiro-Junho, 2021

ISSN 2175-3709 por Hewett Cottrell Watson (1804-1881), Alphonse de Candolle (1806-1893), Alfred Russel Wallace (1823-1913) e Philip Lutley Sclafer (18291913). O limite desta perspectiva vai ser de escala por conta da perspectiva microbiana a partir de Martius Beijerinck (1851-1931) e Lourens Baas Becking (1895-1963). Estas mudanças tecnológicas e teóricas, do micro-molecular, colocam problemas para a leitura da morfologia da paisagem. Ou seja, por que a Geografia não procurou seu objeto de estudo no microscópio?

\section{ALGUMAS CONCLUSÕES PARA O PENSAMENTO GEOGRÁFICO}

Toda esta construção da noção de meio dentro do âmbito da noção de vida influenciou inúmeras ideias e toca no o capítulo mais delicado da Geografia humana, ou seja, aquele clássico problema das influências e das mudanças fisiológicas: "Que o homem não escapa em nada à influência do meio (milieu) local nem em sua constituição física e moral; que as obras que se originam de suas mãos contraem uma marca particular em conformidade com o solo, o clima e os seres vivos que o cercam: nada mais generalizado e mais antigo de ser admitido. Tal área (contrée), tais homens, diz-se" (La Blache, 2012, pág.117-118).

Para La Blache (1911) a existência é solidária pois os "habitantes são unidos por um elo de interesse recíproco, uns beneficiando-se da presença dos outros, dosando reciprocamente, na posição comum, a parte do abrigo e de luz, de umidade e de substâncias químicas, às quais se adapta à existência de cada um dos coassociados... a dependência é reciproca" (La Blache, 2012, pág. 135)

Trata, porém, também de uma visão mais compreensiva do conjunto, de uma visão mais geográfica. Menos simplista diria Ratzel. Para La Blache(1901) se trata de conhecer "a natureza vivente que nos enlaça em múltiplas relações. Do mundo dos seres que nos envolve, o papel dos infinitamente pequenos mal começa a ser imaginado" (La Blache, 2012, pg.122).

No desenvolvimento do método experimental aplicado diretamente à natureza, ampliando a noção de causa-efeito, a geografia tem um papel fundamental, tanto via Kant, quanto via Humboldt. Na descrição física do mundo o Físio significa o deslocamento do mecanicismo matemático-físico de Isaac Newton (16421727) e sua torção pela química, presente em Lavoisier. Foi soado o alerta sobre o "risco" da aplicação do método experimental na sequência da física e da matemática dentro do marco newtoniano à vida. $\mathrm{O}$ risco é a compreensão da vida como coisa mecânica e por analogia como coisa inerte ou máquina pensante.

$\mathrm{O}$ pensamento geográfico esteve presente destes importantes debates da filosofia natural, hoje denominada, ci- 
ências naturais. Humboldt participou do efervescente debate em torno da chamada eletricidade animal. Luigi Galvani (1737-1798) traz esta questão das relações entre anatomia, a física e a química para o debate filosófico da natureza.

Humboldt vislumbrou profundamente esta questão e fez milhares de experimentos em animais, inclusive em si mesmo. Estes experimentos iluminavam as ideias sobre a força vital. Esta questão era central para a filosofia natural e está no cerne daquele debate sobre o inorgânico e orgânico, sobre a matéria, a força e as atividades. Trata-se dos limites do mecanicismo para evidenciar a matéria viva, os seres viventes, a vida propriamente dita. Esta polêmica remete às ideias de Baruch Spinoza (16321677) e David Hume (17111776), derivando em Kant, sobre os limites da experiência humana e da razão e insere-se exatamente neste contexto trazido por Goethe, em específico, a pergunta: o que pode um corpo?

Estes experimentos sobre a eletricidade animal, os debates sobre o animal máquina, sobre a matéria animada e inanimada, sobre a relação entre força e corpo, sobre a matéria e sobre a vida animavam muitos centros intelectuais, científicos, filosóficos e artísticos. $\mathrm{Na}$ medicina era uma questão muito importante. Estavam elaborando uma nova concepção sobre a vida. Blumenbach defendia a tese de que os organismos vivos possuem forças internas e a principal é a bildungstrieb (impulso de formação), a força de formação. O impulso para a criação da vida.

A geologia foi um paradigma importante neste contexto por evidenciar as forças internas da Terra e as relações de causalidade e ganhou enorme interesse por parte de Goethe, Kant e Humboldt. Segundo essa ciência, o tempo tem outras dimensões, dando origem ao conceito de tempo longo, que passa a ser um ingrediente fundamental para a noção de sucessão.

Pela analogia terra-corpo, por forças internas, os corpos se transformam e transformam outros corpos, e, segundo Spinoza a natureza é um jogo de forças. Ele mesmo diz na proposição 29 da primeira parte de sua obra Ética que nenhuma volição pode existir, nem ser determinada a operar, a não ser por outra causa, e, esta por outra, e, assim, por diante, até o infinito. Daí a importância de refletir sobre sua Naturam Naturatam (substâncias) e a Naturam Naturantem (modos).

No final do século XVIII, Goethe escreveu a Metamorfose das Plantas onde estas são formas, variações, de uma Urform (forma arquetípica), primordial e primitiva. Goethe buscava as relações entre esta força interna, a Urform, e o Meio, as forças externas, onde é moldado o organismo. Este é momento do encontro entre Goethe e Humboldt. Humboldt ficou impressionado com as ideias de Goethe sobre anatomia comparada e

\section{GenGRAFARESO}

Revista do Programa de Pós-Graduação em Geografia e do Departamento de Geografia da UFES

Janeiro-Junho, 20Z1

ISSN 2175-3709 
GenGRAFARESO

Revista do Programa de

Pós-Graduação em Geografia e do Departamento de Geografia da UFES

Janeiro-Junho, 2021

ISSN 2175-3709 juntos elaboraram ideias sobre a vida dentro dos seres vivos, encontrando afinidades com as ideias de Blumembach sobre as forças vitais, o Bildungstrieb.

Estas ideias vão se ampliando, da Naturam Naturantem, das Bildungstrieb e das Urform para physiche erdbeschreibung (descrição física do mundo), a verschiedenheit des Landes (comparação de áreas) até o Kosmos (mundo vivo). Humboldt foi fundamental nesta ampliação. Das forças para o organismo e desta para o Todo Orgânico, conectado por forças em feixes de interações funda-se uma nova forma de compreender a natureza. $\mathrm{O}$ conceito de sistema presente nas aulas de Kant sobre a physische geographie (geografia física) interessava muito para Humboldt. A natureza precisava ser interpretada. 


\section{REFERÊNCIAS BIBLIOGRÁFICAS}

BENSAUDE-VICENT, Bernadette \& STENGERS, Isabelle. História da Química (1991). Portugal: Ed. Instituto Piaget, 1996.

BERNARD, Claude. Introdução à Medicina Experimental (1865). Lisboa: Ed. Guimarães. 1978.

BERNARD, Claude. Introduction à l'etude de La médecine expérimentale (1865). Paris: Ed. Bordas, 1966.

BERNARD, Claude. Principes de Médecine expérimentale (1947). $2^{a}$ Ed. Paris: Universitaires de France, 1987.

CANGUILHEM, Georges. Escritos sobre a Medicina. RJ: Forense Universitária, 2005.

CANGUILHEM, Georges. O Conhecimento da Vida (1965). RJ: Forense Universitária, 2012.

CANGUILHEM, Georges. O Normal e o Patológico (1966). $7^{\mathrm{a}}$ Ed. RJ: Forense Universitária, 2011.

CUVIER, George. Leçons D'anatomie Comparée. Paris : Institute National, 1805. Tome Premier, 1805.

DIDEROT E D'ALEMBERT. Enciclopédia, ou Dicionário razoado das ciências, das artes e dos oficios. Ciências da Natureza. SP: Ed. Unesp, 2015, Volume 3, 2015.

DIDEROT E D'ALEMBERT. Enciclopédia, ou Dicionário razoado das ciências, das artes e dos oficios. Metafísica. SP: Ed. Unesp, 2017, Volume 6, 2017.

DUARTE, Rodrigo. Mimeses e Racionalidade. SP: Loyola, 1993.

ENGELS, Friedrich. Dialética da Natureza (1883). SP: Paz e Terra, 1979.

FRAGELLI, Isabel Coelho. A fisiologia e seu discurso. SP: USP, Revista Discurso, v. 47, n. 2, pp. 59-73, 2017.

FRAGELLI, Isabel. Natureza, história, poesia. A exposição simbólica da Bildung. 2014, Tese de Doutorado, Filosofia, FFLCH, USP, 2017.

GOETHE, Johann Wolfgang. A Metamorfose das Plantas (1790). $3^{\mathrm{a}}$ Ed. SP: Ed. Antroposófica, 1997.

GOETHE, Johann Wolfgang. As Afinidades Eletivas (1809). SP: Ed. Nova Alexandria, 1992.

HOLBACH, Paul; Minerais. DIDEROT E D'ALEMBERT. Enciclopédia, ou Dicionário razoado das ciências, das artes e dos oficios. Ciências da Natureza. SP: Ed. Unesp, Volume 3, 2017.

\section{GEOGRAFARESO}

Revista do Programa de Pós-Graduação em Geografia e do Departamento de Geografia da UFES

Janeiro-Junho, 2021

ISSN 2175-3709 


\section{GEOGRAFARESO}

Revista do Programa de

Pós-Graduação em Geografia e do Departamento de Geografia da UFES

Janeiro-Junho, 2021

ISSN 2175-3709
HUMBOLDT, Alexandre de. Cosmos. Essaid'une Description Phisique Du Monde (1847). $4^{\mathrm{a}}$ ed. Paris: Librairie Theodore Morgand, 1866. Tome Deuxiéme, 1866.

HUME, David. Tratado da Natureza Humana (1739). 2a Ed. SP, Editora UNESP, 2009.

KANT, Immanuel. Crítica da Razão Pura. SP: Vozes, 2015.

KANT, Immanuel. Geografia Física (1802). Milano, Tipografia Silvestri, 1809.

KANT, Immanuel. Historia General de La Naturaleza Y Teoria Del Cielo (1755). Buenos Aires, Juarez Ed, 1969.

KANT, Immanuel. Introdução à Geografia Física (1802). GEOgrafia, RJ: UFF, ano IX, No 17, pp. 121-129, 2007.

LA BLACHE, Paul Vidal de. Os Gêneros de Vida na Geografia Humana (1901). Vidal, Vidais. RJ: Bertrand Brasil. 2012.

LA BLACHE, Paul Vidal de. A Geografia Humana: Suas Relações com a Geografia da Vida (1903). Vidal, Vidais. RJ: Bertrand Brasil. 2012.

LA BLACHE, Paul Vidal de. Principes de Geographie Humaine (1921). $4^{\text {a }}$ Ed. Paris : Librairie Armand Colin, 1948.

LAMARCK, J.B.P.A. Philopsophie Zoologique. Tome Premier. Paris : Germer Baillère Librarie, 1830.

LAVOISIER, Antoine-Laurent . Tratado Elementar de Química (1789). SP: Ed. Madras, 2007.

LEBRUN, Gerard. Kant e o fim da Metafisica. SP: Ed. Martins Fontes, 1993.

DAUBENTON, Louis. Descrição. DIDEROT E D'ALEMBERT; Enciclopédia, ou Dicionário razoado das ciências, das artes e dos oficios. Ciências da Natureza. SP: Ed. Unesp, 2015. Volume 3, 2015.

DAUBENTON, Louis. História Natural. DIDEROT E D'ALEMBERT; Enciclopédia, ou Dicionário razoado das ciências, das artes e dos oficios. Ciências da Natureza. SP: Ed. Unesp, 2015. Volume 3, 2015.

LYELL, Charles. Principles of Geology (1830). London: Penguin Classics, 1997.

NIETZSCHE, Feriedrich. Genealogia da Moral. (1887). SP: Companhia das Letras, 1998.

NEWTON, Sir Isaac. Princípios Matemáticos da Filosofia Natural (1686). Os Pensadores. SP: Abril Cultural, 1974. 
PIMENTA, Pedro Paulo. A Trama da Natureza. SP: Ed. Unesp, 2018.

PIMENTA, Pedro Paulo. O destino da Metafísica na Enciclopédia. Diderot- D’Alembert; Enciclopédia. Metafísica. SP: Ed. Unesp, 2017. Volume 6, 2017.

RATZEL, Friedrich. Antropogeografia (1882). Ratzel. SP: Ed. Ática, 1990.

RATZEL, Friedrich. Der Lebensraum: O ESPAÇO DA VIDA: UM ESTUDO BIOGEOGRÁFICO (1901). GEOgraphia, vol. 21, n. 45, jan./abr, UFF, Niterói, pp.107-116, 2019.

RITTER, Carl. Erdkunde. Geographical Studies. Boston: Ed. Gould and Lincoln, 1863.

RITTER, Carl. Géographie Générale Comparéeou Étude de la Terre dans ses rapports avec la Nature et avec l'histoire de l'homme. Bruxelles, Ed. Encyclograpohique. 1837.

SAINT-HILAIRE, Etienne Geoffroy. Principios de Filosofia Zoológica (1830). Buenos Aires Ed. Cactus. 2009.

SCARIM, Paulo. Anatomia comparada e pensamento geográfico moderno. In BOTTER; SCARIM; FARDIN. Comida e saúde em diálogo. O "lugar" da alimentação desde o pensamento antigo até os dias de hoje. Vitória: Editora Cousa, 2021.

SCHELLING, Friedrich Von. Ideias para uma Filosofia da Natureza (1797). Coleção Os Pensadores. SP: Abril Cultural, 1973.

SCHOPENHAUER, Arthur. $O$ Mundo como Vontade $e$ Representação (1818). SP: Unesp, 2005.

SCHOPENHAUER, Arthur. Sobre a Vontade na Natureza (1836). Porto Alegre: L\&PM, 2013.

SPINOZA, Benedictus de. Ética (1675). Belo Horizonte: Editora Autêntica, 2013.

VENEL, Gabriel François. Química (1767). DIDEROT E D'ALEMBERT. Enciclopédia, ou Dicionário razoado das ciências, das artes e dos oficios., Ciências da Natureza. SP: Ed. Unesp, 2015.

\section{GERGRAFARESO}

Revista do Programa de Pós-Graduação em Geografia e do Departamento de Geografia da UFES

Janeiro-Junho, 2021

ISSN 2175-3709 